Figure A

A

$\mathrm{B}$
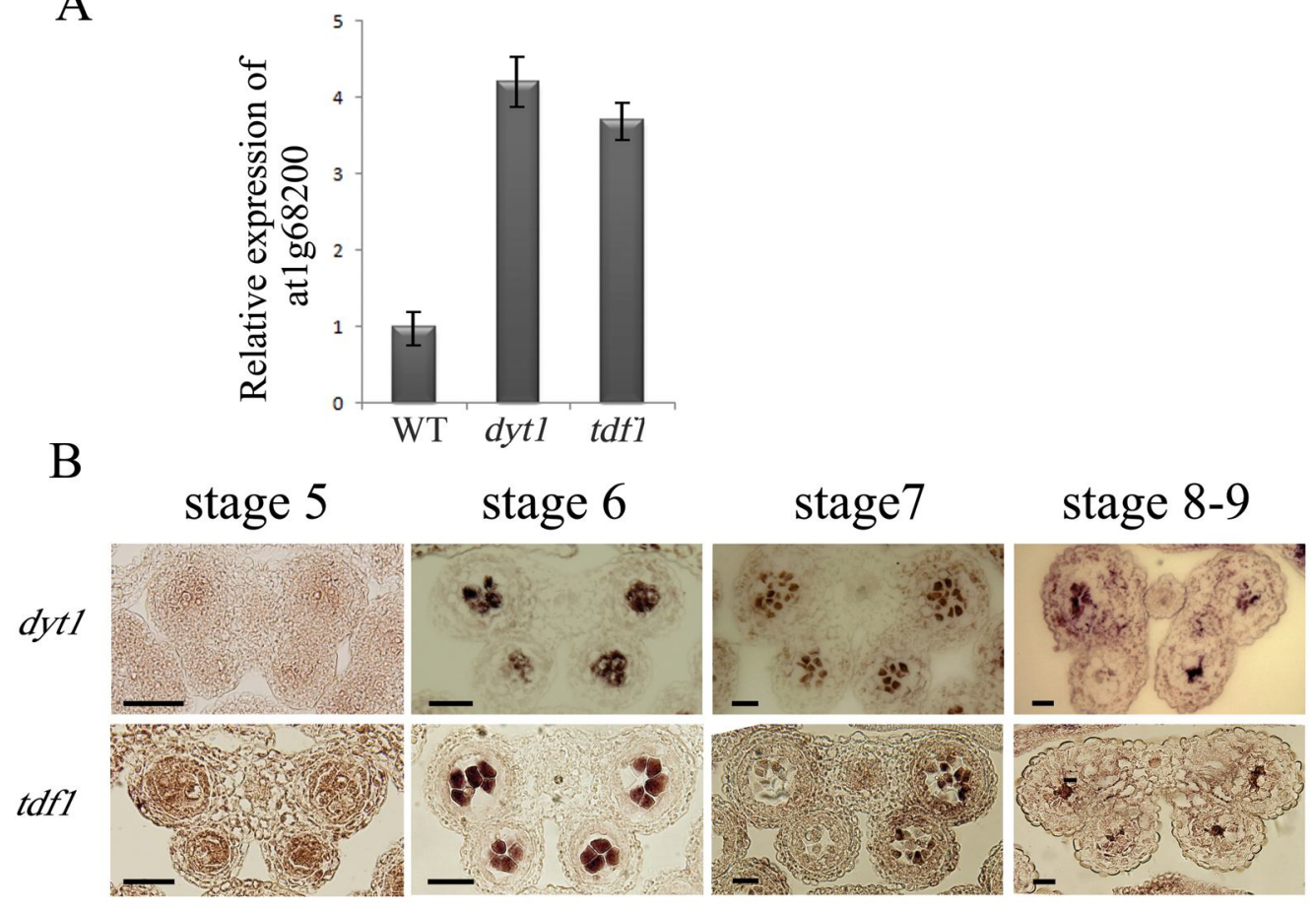

(A) Real-time PCR analysis of AtTTP in in $d y t 1$ and $t d f 1$ floral buds. Each expression level was normalized to that of TUBULIN.

(B) In situ hybridization of the AtTTP transcript in the dyt 1 and $t d f 1$ anther.

Bars $=10 \mu \mathrm{m}$ 


\section{Figure B}
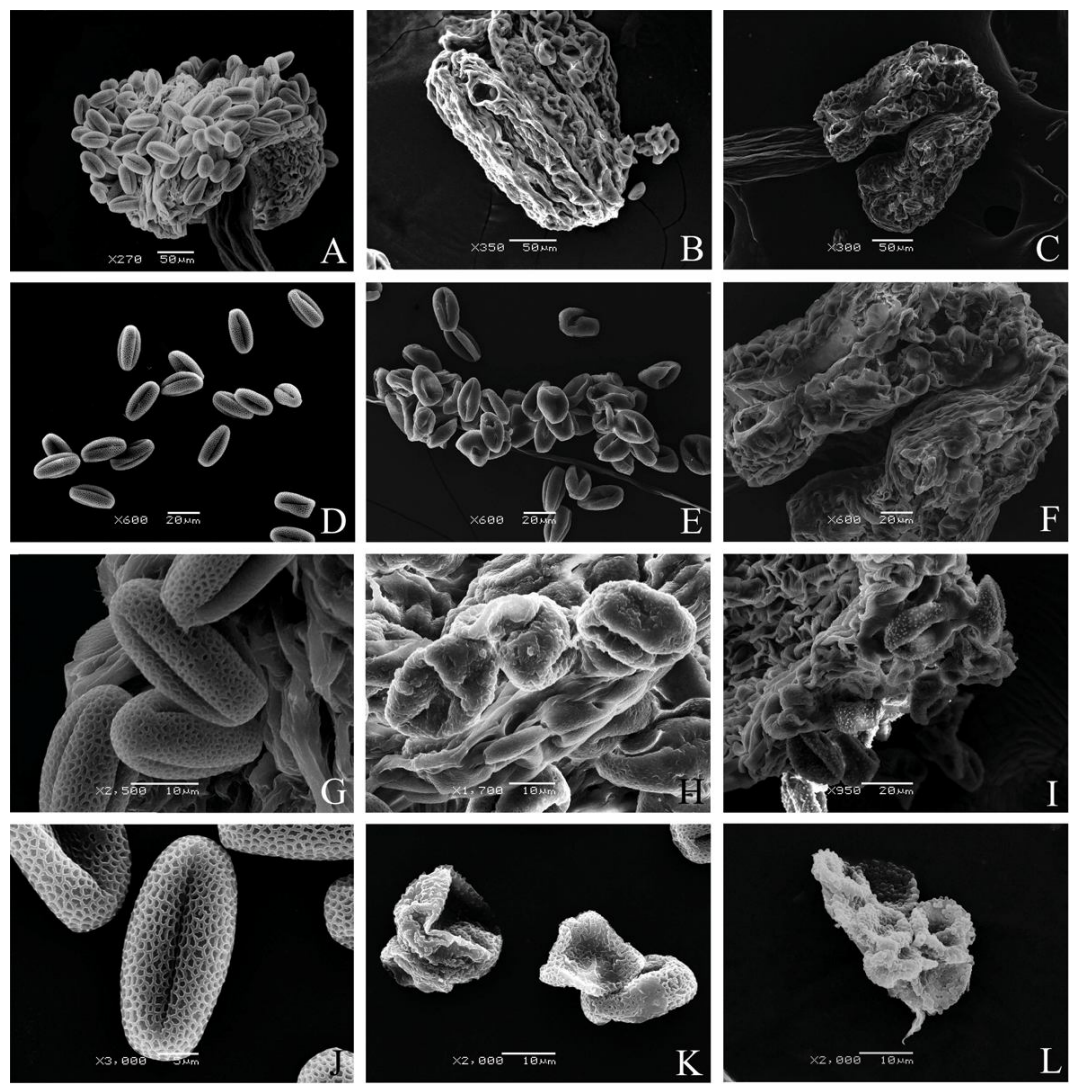

(A, B and C) Dehiscent anthers. Wild-type anther contained numerous pollen grains, whereas most of the AtTTP-OE pollen grains were degenerated and adhered to the anther.

(D, E and F) Pollen grains. Wild-type pollen grains were separated from each other, whereas AtTTP-OE pollen grains adhered to each other (E) and even were inseparable from the anther $(\mathrm{F})$.

(G, H and I) Pollen grains on the dehiscent anther.

(J, K and L) Pollen exine pattern. Wild-type pollen grains have a regular reticulate exine pattern, whereas ruptured AtTTP-OE pollen grains exhibit a spotted exine pattern. 


\section{Figure C}
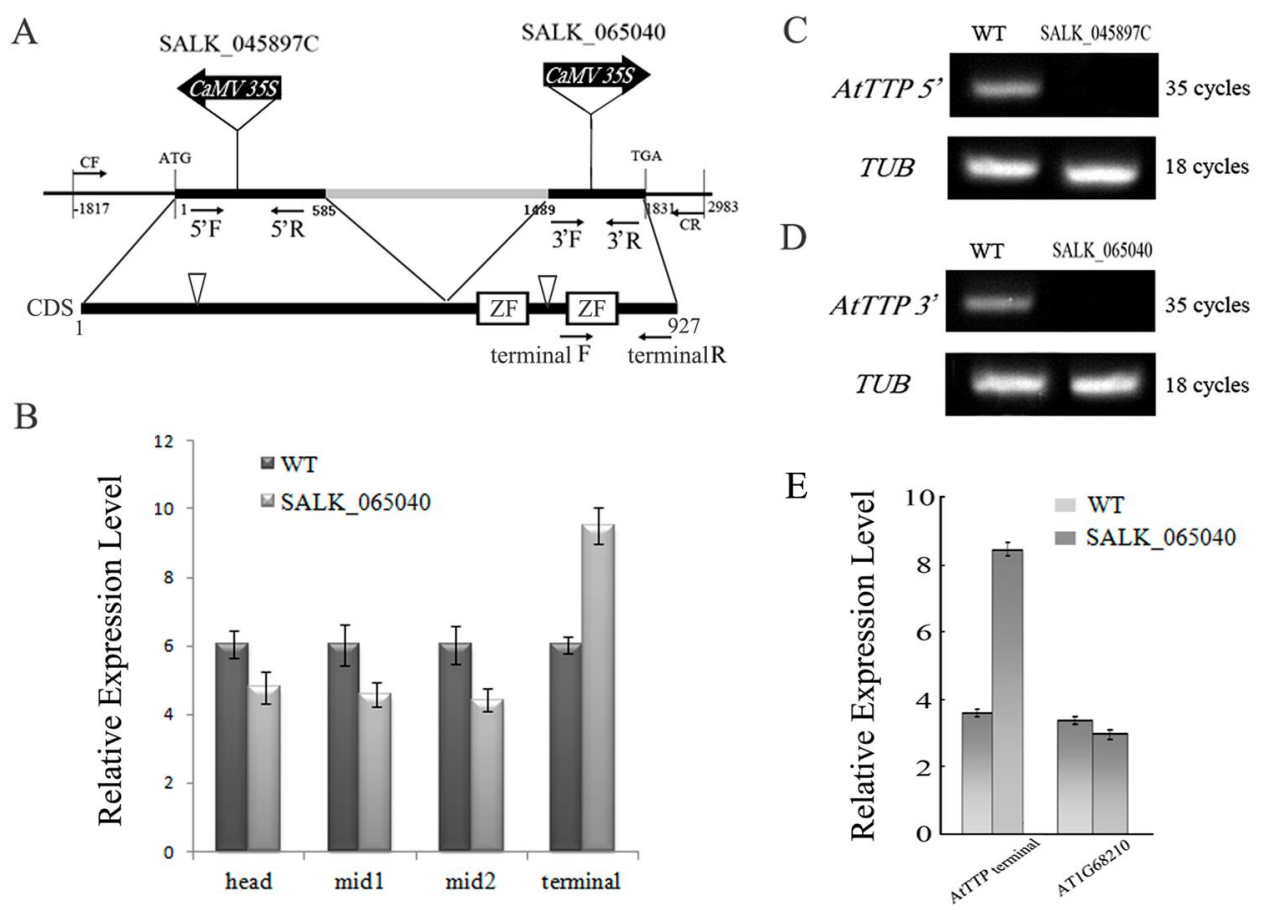

A, the T-DNA insertion of SALK_045897 and the name of primers used in the expression analysis of AtTTP gene.

B, the expression analysis of different part of AtTTP gene in SALK_065040. Head, the $109^{\text {th }}$ to $356^{\text {th }}$ bp of AtTTP CDS sequence. Mid1, the $551^{\text {st }}$ to $740^{\text {th }}$ bp of AtTTP CDS sequence. Mid2, the $436^{\text {th }}$ to $615^{\text {th }}$ bp of AtTTP CDS sequence.

C, the expression analysis of AtTTP gene in both wild type and SALK_045897.

$\mathrm{D}$, the expression analysis of C-terminal of AtTTP gene in both wild type and Salk_065040.

E, the C-terminal over-expression of AtTTP and Atlg68210 in wild type and Salk_065040. 
Figure D
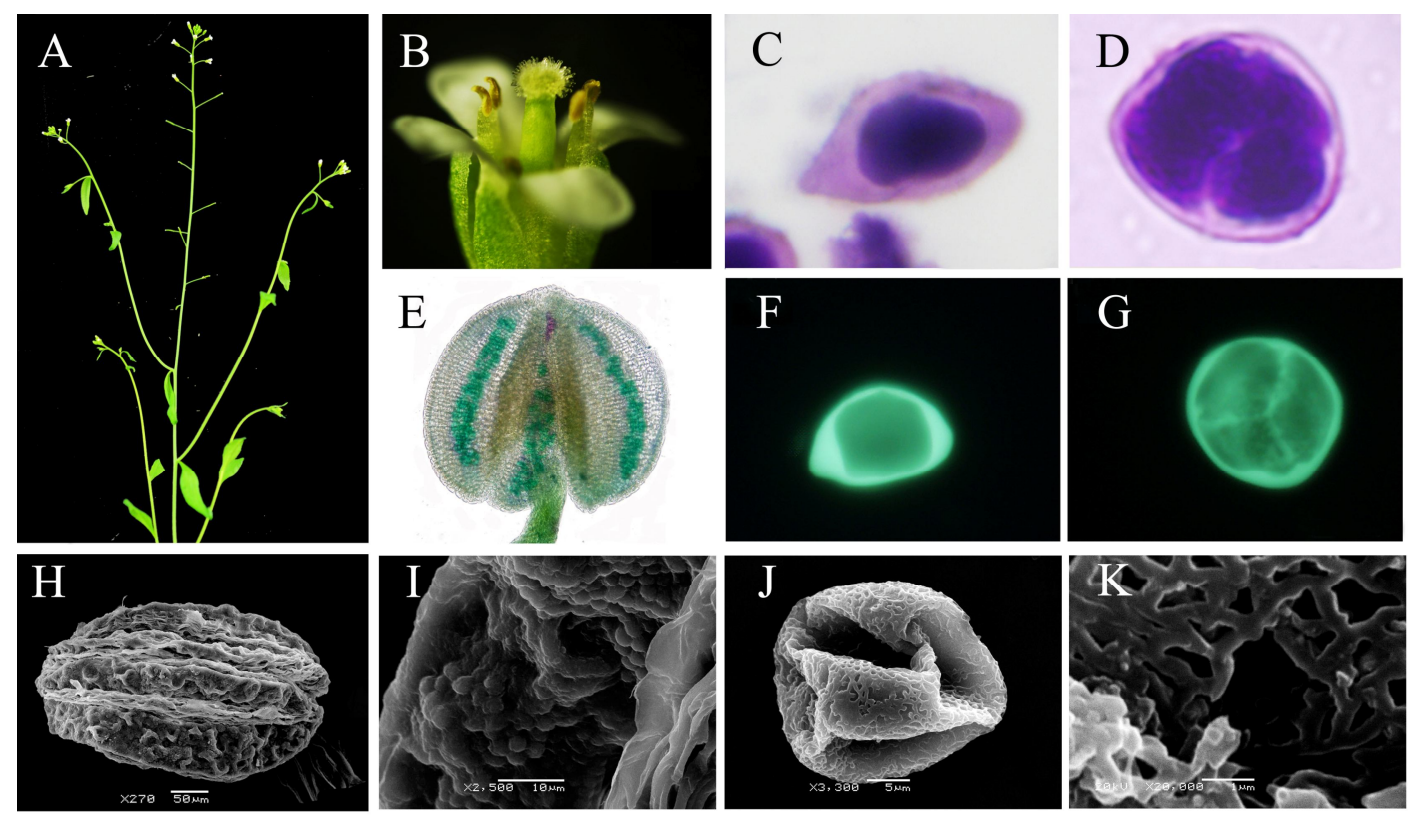

A, Salk_065040 showed male sterility.

B, the flower of Salk_065040

C and D, the pollen mother cells and tetrads of Salk_065040

E, pollen staining of Salk_065040

F and G, callose staining of pollen mother cells and tetrads of Salk_065040

$\mathrm{H}$ to K, the SEM observation of Salk_065040 pollen grains 


\section{Figure E}
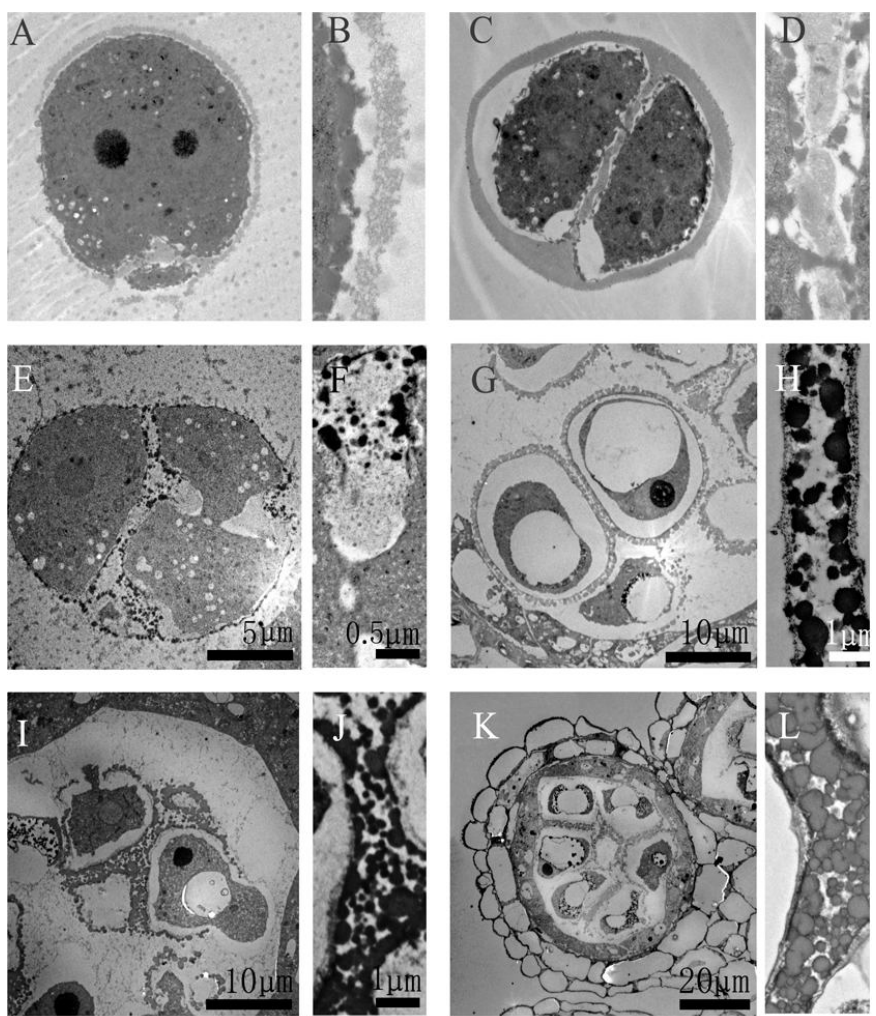

$\mathrm{A}$ and $\mathrm{B}$, pollen mother cell

C to F, tetrads

G to I, adhered microspores

$\mathrm{J}$ to $\mathrm{L}$, adhered microspores and abnormal sporopollenin deposition 